\title{
External Validation of and Factors Associated with the Overuse Index: a Nationwide Population-Based Study from Taiwan
}

\author{
Yu-Chi Tung, $P h D^{\top} \oplus$, Guo-Hong Li, MS ${ }^{\top}$, and Hsien-Yen Chang, PhD $D^{2,3,4}$ \\ ${ }^{1}$ Institute of Health Policy and Management, College of Public Health, National Taiwan University, Taipei, Taiwan; ${ }^{2}$ Department of Health Policy and \\ Management, Johns Hopkins University Bloomberg School of Public Health, Baltimore, MD, USA; ${ }^{3}$ Center for Drug Safety and Effectiveness, Johns \\ Hopkins University, Baltimore, MD, USA; ${ }^{4}$ Center for Population Health Information Technology, Johns Hopkins University, Baltimore, MD, USA.
}

\begin{abstract}
BACKGROUND: The Overuse Index (OI), previously called the Johns Hopkins Overuse Index, is developed and validated as a composite measure of systematic overuse/lowvalue care using United States claims data. However, no information is available concerning whether the external validation of the OI is sustained, especially for international application. Moreover, little is known about which supply and demand factors are associated with the OI.

OBJECTIVE: We used nationwide population-based data from Taiwan to externally validate the OI and to examine the association of regional healthcare resources and socioeconomic factors with the OI.
\end{abstract}

DESIGN AND PARTICIPANTS: We analyzed 1,994,636 beneficiaries randomly selected from all people enrolled in the Taiwan National Health Insurance in 2013.

MAIN MEASURES: The OI was calculated for 2013 to 2015 for each of 50 medical regions. Spearman correlation analysis was applied to examine the association of the OI with total medical costs per capita and mortality rate. Generalized estimating equation linear regression analysis was conducted to examine the association of regional healthcare resources (number of hospital beds per 1000 population, number of physicians per 1000 population, and proportion of primary care physicians [PCPs]) and socioeconomic factors (proportion of low-income people and proportion of population aged 20 and older without a high school diploma) with the OI.

RESULTS: Higher scores of the OI were associated with higher total medical costs per capita $(\rho=0.48, P<0.001)$ and not associated with total mortality $(\rho=-0.01, P=$ 0.882). Higher proportions of PCPs and higher proportions of low-income people were associated with lower scores of the OI $(\beta=-0.022, P=0.016$ and $\beta=-0.224, P$ $<0.001$, respectively).

CONCLUSIONS: Our study supported the external validation of the OI by demonstrating a similar association within a universal healthcare system, and it showed the

Electronic supplementary material The online version of this article (https://doi.org/10.1007/s11606-020-06293-0) contains supplementary material, which is available to authorized users.

Prior Presentations None.

Received January 21, 2020

Accepted October 5, 2020

Published online October 15, 2020 association of a higher proportion of PCPs and a higher proportion of low-income people with less overuse/lowvalue care.

KEY WORDS: overuse; low-value care; measurement; regional variation.

J Gen Intern Med 36(2):438-46

DOI: $10.1007 / \mathrm{s} 11606-020-06293-0$

(C) Society of General Internal Medicine 2020

$\mathrm{T}$ o counter the rapidly increasing healthcare spending around the world, ${ }^{1}$ there is global interest in optimizing the delivery of health services, exemplified by increased use of high-value care or services and reduced use of low-value care or services. ${ }^{2,3}$ Overuse/low-value care is defined as the provision of procedures and treatments that provide little or no benefit to beneficiaries while increasing the costs of healthcare. ${ }^{2,4-9}$ In the United States (US), estimates of spending on overuse vary widely. ${ }^{7}$ Conservative estimates according to direct measurement of individual services range from 6 to $8 \%$ of total healthcare spending. ${ }^{10}$ Studies of geographic variation (an indirect measure) put the proportion of Medicare spending on overuse closer to $29 \% .{ }^{11}$ Recent studies estimate that 14 to $25 \%$ of Medicare beneficiaries, $8 \%$ of privately insured adults, and $7 \%$ of adult military beneficiaries experience at least one overuse event per year. ${ }^{6,8,9,12}$

Overuse occurs regardless of whether healthcare providers are paid by fee-for-service or salary in market-driven and highly regulated systems, ${ }^{1,13}$ or in universal healthcare systems (e.g., United Kingdom (UK), Canada, and Taiwan). ${ }^{7,}$ 14, ${ }^{15}$ However, it is difficult to use measures of individual lowvalue services to compare the overall overuse status across countries and regions. Thus, Segal et al. used claims data to develop the Overuse Index (OI), previously called the Johns Hopkins Overuse Index (JHOI), ${ }^{6}$ which is the only composite index constructed and validated to measure regional variation in overall overuse. ${ }^{6,8}$ The OI is a normalized measure, not an absolute measure. The OI was originally validated in the US Medicare population by demonstrating the relation of the OI with medical costs and no relation with total mortality, ${ }^{6,16,17}$ 
and then externally validated in a commercially insured US adult population. $8,16,17$ Nevertheless, up to now, the OI has not been externally validated in a nationwide population, especially for other countries, regardless of differences in the healthcare systems or population characteristics. Such external validation will provide an empirically robust ground for healthcare policymakers to initiate polices to reduce systematic overuse, as measured by the OI, which might then be used as a tool to evaluate the impact of national or local policies.

Given that we may identify the existence of systematic overuse through the OI, the next important step is to understand the regional supply and demand factors (regarding socioeconomic factors) of overuse so that policy interventions may be delivered. To the best of our knowledge, only two prior studies have shown the regional-level association of higher ratio of specialists to primary care physicians (PCPs) and lower proportion of low-income people with higher composite overuse scores. ${ }^{18,19}$ Nevertheless, the composite overuse scores have not been validated. Regarding the OI, two studies have found that the supply of regional healthcare resources was associated with the OI, including the number of hospital beds, ${ }^{20}$ and the number of PCPs. ${ }^{20,21}$ However, so far, there has been no study using nationwide populationbased data to examine the association of regional supply and demand factors with the OI.

This study, using nationwide population-based claims data from Taiwan with an universal-access, free at the point of service, healthcare system (Online Appendix 1), calculated the OI, explored the external validation of the OI by confirming its association with medical costs and no association with total mortality, and examined the association of regional healthcare resources and socioeconomic factors with the OI.

\section{METHODS}

\section{Data Source}

This study used Taiwan's national research database provided by the Health and Welfare Data Science Center, Ministry of Health and Welfare (MOHW). The database is a de-identified national database that includes the National Health Insurance Research Database (e.g., inpatient, outpatient, and prescription drug claims, and beneficiaries) and other health-related files (e.g., cause of death, and medical facilities). ${ }^{22}$ Regional-level socioeconomic characteristics' data were taken from the Demographic Statistics from the Ministry of the Interior. Our conceptual framework is shown in Figure 1 based on literature review and data availability. $6,8,18,19,23-30$ This study was approved by the Institutional Review Board of the National Taiwan University Hospital.

\section{Study Population}

The study population included all NHI beneficiaries 18 years of age or older in 2013. We simply randomly selected 2 million adult beneficiaries from the study population of about 19 million. Comparison of sample characteristics (sex, age, and insured amount) with the study population characteristics showed no significant difference (Online Appendix 2). The sample was representative of the adult beneficiary population. Beneficiaries were assigned to a sub-medical region $(N=50)$ as defined by the $\mathrm{MOHW}^{31}$ based on the geographic location of the beneficiary's residence. ${ }^{32-34}$ We excluded 5181 beneficiaries not residing in the 50 sub-medical regions, ${ }^{6,21}$ and 183 beneficiaries with symptomatic carotid artery stenosis (CAS) based on the eligibility criteria of the OI regarding CAS screening. ${ }^{6}$ The final sample size came down to $1,994,636$ beneficiaries. Because the population structure is stable over time, the sample was used to calculate the OI for each year from 2013 to 2015. The sample sizes in 2014 and 2015 were 1,978,267 and 1,961,564 beneficiaries, respectively (Online Appendix 3).

\section{Variables}

Calculation of the $\mathrm{OI}$. The OI consists of 20 clinically diverse claims-based measures of overuse that are aggregated into an index. ${ }^{6}$ The OI measures came from the Choosing Wisely Campaign, Institute of Medicine, UK's National Health Service, and other reputable professional organizations (Online Appendix 4). ${ }^{20,35}$ However, we excluded two measures from the composition of the OI: serological tests for Helicobacter pylori and stress echocardiography for acute chest pain. Serological tests for Helicobacter pylori are not reimbursed in Taiwan. The rate of use of stress echocardiography for acute chest pain is too rare $(<0.5 \%$ ). In addition, for uncomplicated acute rhinosinusitis, both sinus computed tomography (CT) and antibiotics were included according to the Choosing Wisely campaign. ${ }^{36}$

Based on the calculation of the OI, ${ }^{6,8,20,21}$ the patientspecific factors in the model of the OI included sex, age, and comorbid conditions. The Charlson-Deyo Comorbidity Index (CCI) was used to quantify the comorbidities of the beneficiaries. $^{23}$ This index is the sum of weighted scores based on the presence or absence of 17 different medical conditions.

Validation of the $\boldsymbol{O I}$. Costs per capita were calculated as annual total regional medical costs divided by the total number of beneficiaries in a region. Total regional medical costs included all NHI inpatient, outpatient, and prescription drug costs in a region. Clinical benefit was measured as the total mortality rate. ${ }^{6,8}$ The regional mortality rate was risk adjusted for patient sex, age, and CCI, and it was calculated as the observed mortality divided by the expected mortality in a region and then multiplied by the total mortality rate. ${ }^{6}$

\section{Identification of Regional Factors Associated with the OI.} The supply of regional health resources was measured as the number of hospital beds per 1000 residents, the number of physicians per 1000 residents, and the proportion of PCPs. ${ }^{24}$ 26 The number of hospital beds per 1000 residents provides a measurement of the resources available for delivering services 


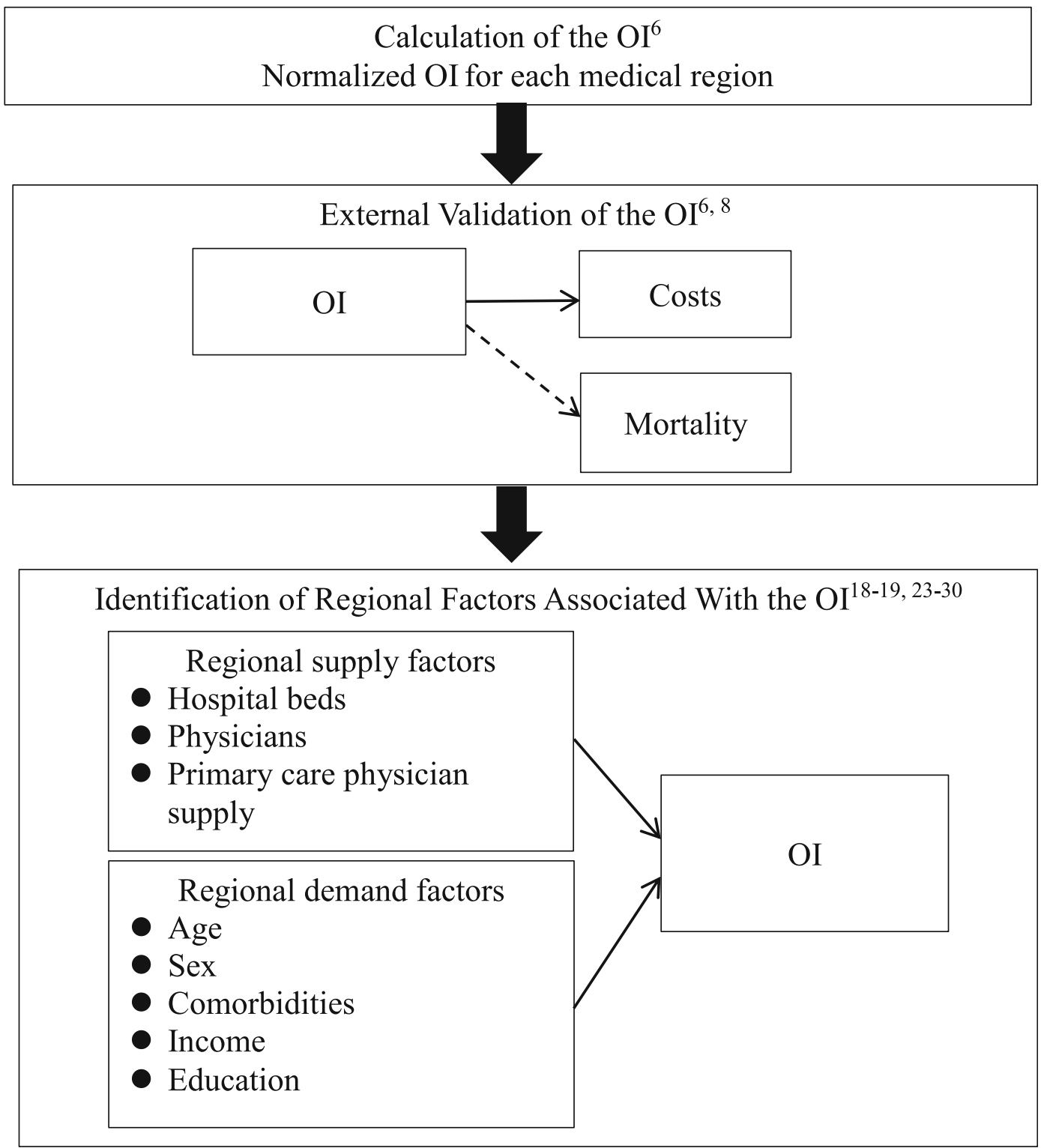

Figure 1 Conceptual framework: Calculation of, validation of, and factors associated with the Overuse Index (OI). Solid lines indicate that an association was hypothesized, and dash lines indicate that no association was hypothesized.

to inpatients in hospitals. ${ }^{24}$ The proportion of PCPs was calculated by dividing the number of PCPs by the total number of physicians. ${ }^{25,}{ }^{26}$ The regional socioeconomic characteristics were measured as the proportion of lowincome population ${ }^{18,19}$ and the proportion of the population aged 20 and older without a high school diploma. ${ }^{27-30}$

\section{Statistical Analysis}

Calculation of the OI. The OI was calculated using multilevel regression to model whether an eligible beneficiary received an overuse measure as a function of beneficiary sex, age, and comorbid conditions, a fixed effect for each of the 18 overuse measures, and a fixed effect for each of the 50 medical regions. The latter coefficient captured the latent tendency of a medical region to overuse diverse healthcare resources. This estimate was then standardized to create the OI as a $Z$ score (Online Appendix 5). ${ }^{6,8}$ We prepared a map showing the normalized OI for each medical region using ArcGIS (Esri, Redland, CA).

Validation of the OI. Regarding testing the external validation of the OI, we used Spearman's correlation coefficients to examine the association of the OI with total medical costs per capita and mortality rate. ${ }^{6}$

Identification of Regional Factors Associated with the OI. For identifying regional factors associated with the OI, we adopted multivariable linear regression analysis with the generalized estimating equation (GEE) technique to examine the relative association of regional healthcare resources and socioeconomic factors with the OI. The 
GEE with the independent correlation structure was used to account for repeated measurements (3 years) per medical region because the correlation model had the smallest quasi-likelihood information criterion value. ${ }^{37}$ The SAS statistical software (version 9.4) was used for analysis. A two-sided $P<0.05$ was considered statistically significant.

\section{RESULTS}

Among 1,994,636 eligible beneficiaries, $48.7 \%$ were men, the mean age was 45.7 years, $13.8 \%$ were 65 years old and above, the mean CCI was 0.6 , and $27.8 \%$ had at least one comorbidity of the CCI (CCI score of 1 or greater).

Table 1 presents the descriptive statistics of individual indicators of the OI for 2013 to 2015. Among these beneficiaries, about $13 \%$ experienced at least one overuse event, and most of the statistics of the indicators were stable during 2013 to 2015. For individual indicators, the highest use rate was for abdomen $\mathrm{CT}$ with and without contrast. From the regionallevel analyses, the OI indicators had rates of use that varied across medical regions. Figure 2 shows the geographic distribution of the OI by medical regions in 2013. The OI showed variation across medical regions. Systematic overuse was more prevalent in a number of coastal regions (especially in metropolitan regions), but the southeastern regions (classified as rural areas) had less systematic overuse.

Table 2 presents the characteristics of the medical regions including population demographics, healthcare supply, socioeconomic factors, OI, medical costs, and mortality. On average in 2013, each medical region had 6.0 hospital beds per 1000 population, 1.5 physicians per 1000 population, $45.3 \%$ PCPs, $2.2 \%$ low-income people, $39.5 \%$ population aged 20 and older without a high school diploma, NT\$23,640 medical costs per capita, and $0.8 \%$ total mortality. The OI had a minimum of -3.5 and maximum of 1.9 between 2013 and 2015 (Online Appendix 6).

Figure 3 shows the correlations between the OI and total costs per capita and mortality rate, respectively. The index was positively correlated with total costs per capita $(\rho=0.48, P<$ $0.001)$ and was not correlated with total mortality rate $(\rho=-$ $0.01, P=0.882$ ).

Table 3 demonstrates the results of the GEE linear regression analysis of the OI. Regional PCP supply and income status were associated with systematic overuse. For every $1 \%$ increase in the proportion of PCPs, there was a $0.022-$ point decrease in the $\mathrm{OI}(P=0.016)$. For every $1 \%$ increase in the proportion of low-income people, there was a 0.224-point decrease in the OI $(P<0.001)$.

\section{DISCUSSION}

This study was the first research to apply the OI internationally, and to examine the association of regional healthcare resources and socioeconomic factors with systematic overuse/low-value care using a nationwide sample from Taiwan. We found that higher scores of the OI were associated with higher total medical costs per capita, and not associated with total mortality rate. We also found that a higher proportion of PCPs and a higher proportion of low-income people were associated with less systematic overuse.

The findings of the positive association between OI scores and total medical costs per capita and no association between OI scores and total mortality rate are similar to those findings in Medicare fee-for-service beneficiaries aged 65 years or older, ${ }^{6}$ and US private health insurance beneficiaries aged 18 to 64 years. ${ }^{8}$ Our analyses using a nationwide sample from Taiwan may support the external validation of the OI. The OI varies directly with healthcare costs and it does not vary directly with measures of clinical benefit. ${ }^{6}$ The OI could be applied in other populations or countries, regardless of differences in the healthcare systems or population characteristics.

The rate of people who had one of these overuse indicators (including antibiotics) of the Taiwan's healthcare system was 13\% during 2013 to 2015, similar to that (excluding antibiotics) of the Medicare system in 2008 (14\%). ${ }^{6}{ }^{35}$ However, the rate (excluding antibiotics) of the Taiwan's healthcare system was $8 \%$, similar to that of certain US private health insurance systems from January 2011 to June 2015 (8\%), ${ }^{8}$ and higher than that of the US Military Health System in 2014 (7\%). In Canada's universal healthcare system, prior research found that $4 \%$ of Alberta adults had one of the 10 low-value tests between 2012 and $2015 .{ }^{15}$ Overuse occurs in fragmented healthcare systems that lack continuity, coordination, and integration of care, including US's, Canada's, and Taiwan's, regardless of universal healthcare systems that have universal access to healthcare. ${ }^{26}$ The "right" rate for these overuse measures is not expected to be zero, but the differences across regions, systems, or countries suggest what is achievable.

The finding of the regional-level association between a higher proportion of PCPs and lower OI scores is consistent with studies by Zhou et al. (using the number of PCPs per 1000 residents and the $\mathrm{OI})^{20}$ and Colla et al. (using specialist to primary care ratio and composite overuse scores, calculated based on 11 or 7 Choosing Wisely-identified low-value services). ${ }^{18,19}$ One Canadian study found that patients living in regions with a higher ratio of specialists to PCPs had more utilization of 10 low-value tests in Alberta. ${ }^{15}$ Prior regionallevel US research found that higher proportions of PCPs were associated with decreased utilization, including inpatient admissions, emergency department visits, and surgeries. ${ }^{25}$ Primary care physicians serve as the point of first contact and decrease healthcare utilization through enhanced coordination of care and a preventive care focus. ${ }^{25,} 38$

The finding of the regional-level association between a higher proportion of low-income people and lower OI scores is consistent with Colla et al. ${ }^{18,19}$ One Canadian study found that patients living in areas with high neighborhood income had more utilization of 10 low-value tests. ${ }^{15}$ Previous US 


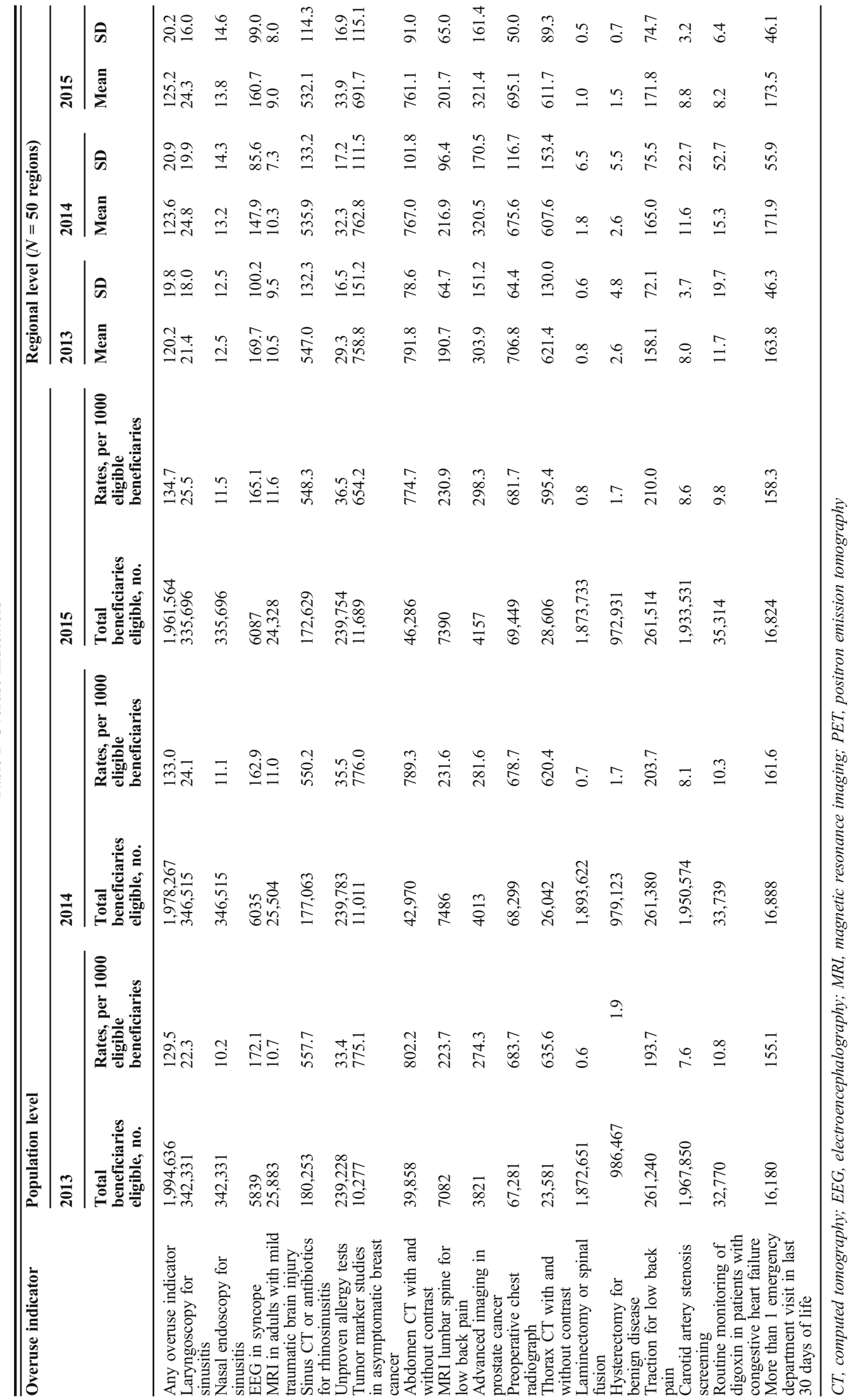




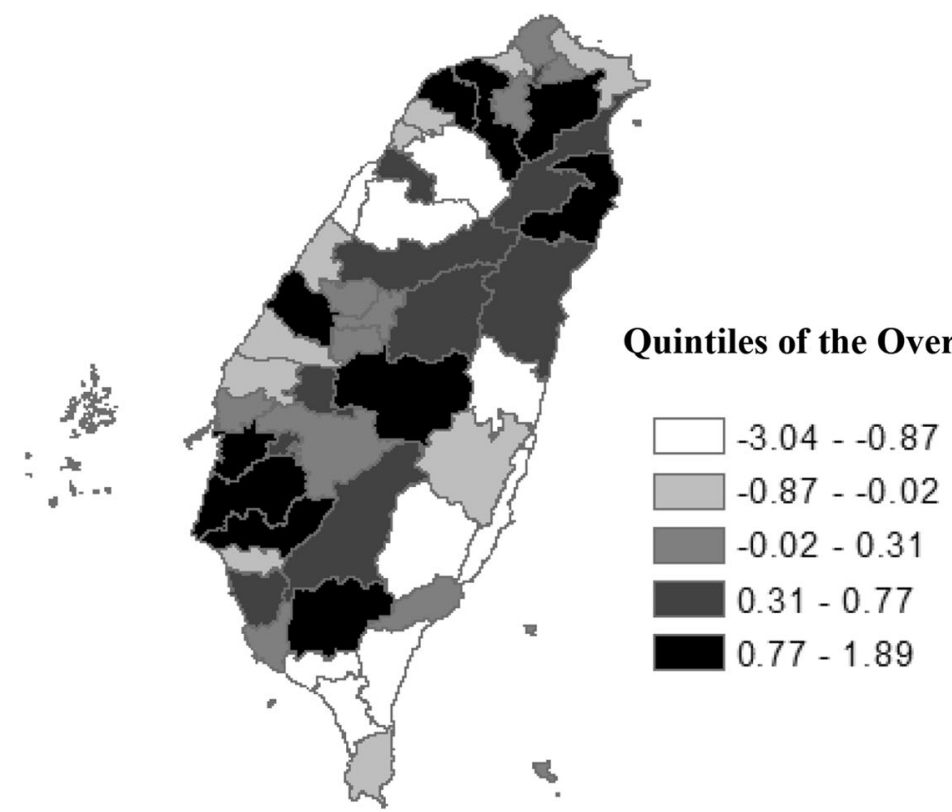

Figure 2 Variation in the Overuse Index calculated for each of 50 medical regions in 2013.

studies found that Medicare patients living in higher income

Table 2 Regional Characteristics $(N=\mathbf{5 0})$

\begin{tabular}{|c|c|c|c|c|c|c|}
\hline & \multicolumn{2}{|l|}{2013} & \multicolumn{2}{|l|}{2104} & \multicolumn{2}{|l|}{2015} \\
\hline & Mean & SD & Mean & SD & Mean & SD \\
\hline Male, \% & 49.9 & 2.1 & 50.0 & 2.2 & 49.8 & 2.1 \\
\hline $\begin{array}{l}\text { Mean age, } \\
\text { years }\end{array}$ & 47.6 & 3.0 & 48.4 & 3.0 & 49.2 & 3.0 \\
\hline Mean CCI & 0.7 & 0.2 & 0.7 & 0.2 & 0.7 & 0.2 \\
\hline $\begin{array}{l}\text { Number of } \\
\text { hospital } \\
\text { beds per } \\
1000 \\
\text { population }\end{array}$ & 6.0 & 4.2 & 5.9 & 4.3 & 5.9 & 4.2 \\
\hline $\begin{array}{l}\text { Number of } \\
\text { physicians } \\
\text { per } 1000 \\
\text { population }\end{array}$ & 1.5 & 0.7 & 1.5 & 0.7 & 1.6 & 0.7 \\
\hline $\begin{array}{l}\text { Proportion } \\
\text { of primary } \\
\text { care } \\
\text { physicians, } \\
\%\end{array}$ & 45.3 & 16.9 & 45.1 & 16.4 & 45.2 & 17.1 \\
\hline $\begin{array}{l}\text { Proportion } \\
\text { of low- } \\
\text { income peo- } \\
\text { ple, } \%\end{array}$ & 2.2 & 1.7 & 2.1 & 1.7 & 2.0 & 1.5 \\
\hline $\begin{array}{l}\text { Proportion } \\
\text { of } \\
\text { population } \\
\text { aged } 20 \text { and } \\
\text { older } \\
\text { without a } \\
\text { high school } \\
\text { diploma, \% }\end{array}$ & 39.5 & 10.5 & 38.5 & 10.3 & 43.3 & 14.6 \\
\hline $\begin{array}{l}\text { Overuse } \\
\text { Index }\end{array}$ & 0.0 & 1.0 & 0.0 & 1.0 & 0.0 & 1.0 \\
\hline $\begin{array}{l}\text { Total costs } \\
\text { per capita, } \\
\text { NT\$ }\end{array}$ & 23,640 & 9111 & 24,757 & 9491 & 25,723 & 10,003 \\
\hline $\begin{array}{l}\text { Total } \\
\text { mortality } \\
\text { rate, \% }\end{array}$ & 0.8 & 0.1 & 0.9 & 0.1 & 0.9 & 0.1 \\
\hline
\end{tabular}

NT\$30 equaled \$1. CCI, Charlson-Deyo Comorbidity Index; NT\$, new Taiwan dollars census tracts had more overuse of imaging for prostate cancer, ${ }^{29,30}$ and Medicare beneficiaries with higher income were more likely to use low-value cancer screenings and, in turn, received larger net subsidies from Medicare. ${ }^{39}$ Beneficiaries living in areas of higher income were more likely to receive low-value imaging. ${ }^{40}$ This may be a result of increased beneficiaries' demand and better access to low-value care. ${ }^{40}$ Beneficiaries living in areas of higher income may be more likely to expect to receive low-value care, ${ }^{41}$ may possess generous supplemental insurance, and may be more likely to afford cost sharing and, therefore, more likely to access low-value care. ${ }^{40}$ Previous literature underscored socioeconomic disparities in underuse of guideline-recommended healthcare services, reflecting a maldistribution of resources driven by socioeconomic disparities. ${ }^{1,42,43}$ Until now, for diminishing waste in the healthcare system and advocating for value-based healthcare, the socioeconomic disparities in discretionary service use have recently been emphasized. ${ }^{1,} 39$ Therefore, to reduce waste in the healthcare system and improve resource allocation toward value-based healthcare, income disparities in the use of low-value care services need to be addressed.

There are two limitations of our study that deserve comment. First, a common challenge faced by researchers comes from using the claims data to definitively identify overuse. ${ }^{5,6}$, $8,9,15,18-21,35,39$ Claims may not provide enough details of important disease (e.g., cancer) history or symptoms that clinically justified the screening, which would appear as low value in claims data. ${ }^{39}$ Although claims data might not be ideal for measurement of patient risk or symptoms, we validated that the OI was associated with total costs, and not associated with total mortality, which is consistent with previous studies. ${ }^{6}{ }^{8} \mathrm{We}$ are not saying that the rate of overuse should be zero - just that there probably should not be as much variation between regions as you see here. Second, this result was from 

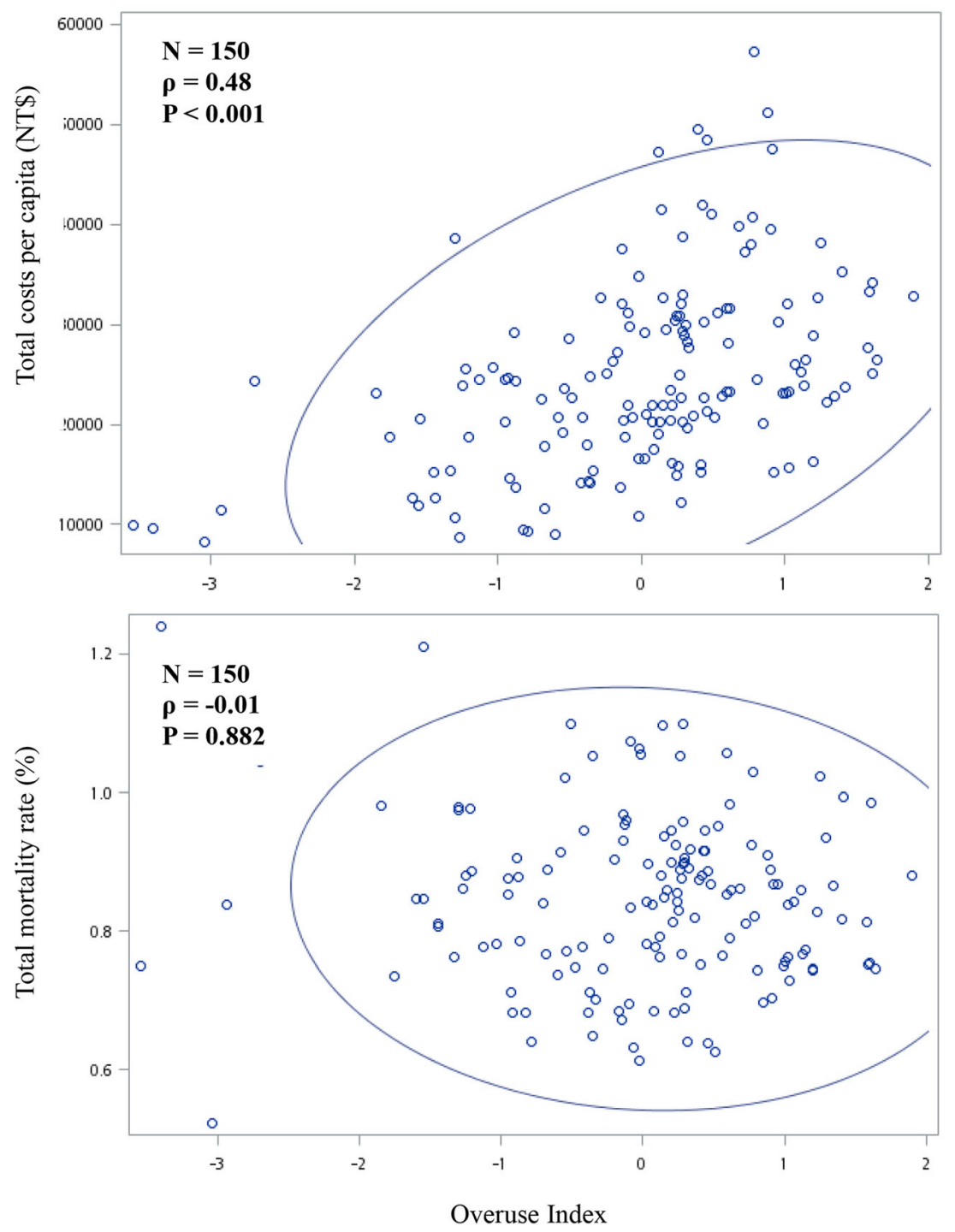

Figure 3 Scatter plots relating total costs per capita and mortality rates to the Overuse Index. NT\$30 equaled \$1. Ellipse represents the 95\% confidence interval. NT\$, new Taiwan dollars.

Taiwan and there may be particular aspects of the Taiwan's healthcare system that could not be applied and generalized to other countries.

Table 3 GEE Linear Regression of Overuse Index $(N=150)$

\begin{tabular}{|c|c|c|c|}
\hline & $\beta$ & SE & $P$ \\
\hline Male, \% & $\overline{0} .088$ & 0.078 & 0.254 \\
\hline Mean age, years & $-\overline{0} 062$ & 0.065 & 0.343 \\
\hline Mean CCI & 1.203 & 0.935 & 0.198 \\
\hline $\begin{array}{l}\text { Number of hospital beds per } 1000 \\
\text { population }\end{array}$ & $-\overline{0} 010$ & 0.016 & 0.537 \\
\hline $\begin{array}{l}\text { Number of physicians per } 1000 \\
\text { population }\end{array}$ & $\overline{0}-169$ & 0.196 & 0.389 \\
\hline Proportion of primary care physicians, $\%$ & $\overline{0}-022$ & 0.009 & 0.016 \\
\hline Proportion of low-income people, $\%$ & 0.224 & 0.063 & $\begin{array}{l}< \\
0.001\end{array}$ \\
\hline $\begin{array}{l}\text { Proportion of population aged } 20 \text { and } \\
\text { older without a high school diploma, } \%\end{array}$ & $\overline{-} .002$ & 0.005 & 0.706 \\
\hline
\end{tabular}

CCI, Charlson-Deyo Comorbidity Index; GEE, generalized estimating equation; SE, standard error
Our national population-based study supported the external validation of the OI by demonstrating a similar association within a universal healthcare system, and it showed the association of the proportion of PCPs and the proportion of lowincome people with the OI. The OI appears to yield similar findings between the OI with total medical costs and mortality in different countries. The OI could be used as the measurement of systematic overuse/low-value care (i.e., using a portfolio of potential overuse indicators as a proxy for the underlying phenomenon) and as a bellwether for trends in overuse across countries or systems. This information of the OI could encourage healthcare systems or providers to address the structural and system-wide determinants of overuse rather than focus on individual overuse indicators. Moreover, it could be more difficult to manipulate the $\mathrm{OI}$ in comparison with an individual overuse indicator serving as a measure. This study also supports increased attention to primary care as a strategy to lower systematic overuse. Increased attention to the PCP workforce and PCPs' distribution across regions relative to the 
number of specialists may have an important role in the effort to reduce systematic overuse. Selectively increasing beneficiary cost sharing for high-income groups and/or for lowvalue care may partially counter the unfair distribution of insurance benefits resulting from overuse. Identifying factors affecting overuse may provide new avenues to implement quality improvement initiatives through which overuse reduction may be best achieved.

Acknowledgments: The authors would like to thank Dr. Jodi B. Segal for her comments on drafts.

Corresponding Author: Yu-Chi Tung, PhD; Institute of Health Policy and Management, College of Public Health, National Taiwan University, Taipei, Taiwan (e-mail: yuchitung@ntu.edu.tw).

Funding The study was supported by grants from the Ministry of Science and Technology (MOST107-2410-H-OO2-227-MY3).

\section{Compliance with Ethical Standards:}

This study was approved by the Institutional Review Board of the National Taiwan University Hospital.

Conflict of Interest: The authors declare that they do not have a conflict of interest.

\section{REFERENCES}

1. Saini V, Brownlee S, Elshaug AG, Glasziou P, Heath I. Addressing overuse and underuse around the world. Lancet. 2017;390:105-107.

2. Porter ME. What is value in health care? N Engl J Med 2010;363:24772481.

3. Elshaug AG, Rosenthal MB, Lavis JN, et al. Levers for addressing medical underuse and overuse: achieving high-value health care. Lancet. 2017;390:191-202.

4. Chassin MR, Galvin RW. The urgent need to improve health care quality. Institute of Medicine National Roundtable on Health Care Quality. JAMA. 1998;280:1000-1005.

5. Chan KS, Chang E, Nassery N, Chang HY, Segal JB. The state of overuse measurement: a critical review. Med Care Res Rev 2013;70:473496.

6. Segal JB, Nassery N, Chang HY, Chang E, Chan $\mathbf{K}$, Bridges JF. An index for measuring overuse of health care resources with Medicare claims. Med Care 2015;53:230-236.

7. Brownlee S, Chalkidou $\mathbf{K}$, Doust $\mathbf{J}$, et al. Evidence for overuse of medical services around the world. Lancet. 2017;390:156-168.

8. Oakes AH, Chang HY, Segal JB. Systemic overuse of health care in a commercially insured US population, 2010-2015. BMC Health Serv Res 2019; 19:280

9. Koehlmoos TP, Madsen CK, Banaag A, Haider AH, Schoenfeld AJ, Weissman JS. Assessing low-value health care services In the Military Health System. Health Aff (Millwood) 2019;38:1351-1357.

10. Berwick DM, Hackbarth AD. Eliminating waste in US health care. JAMA. 2012;307:1513-1516.

11. Wennberg JE, Fisher ES, Skinner JS. Geography and the debate over Medicare reform. Health Aff (Millwood). 2002;Suppl Web Exclusives:W96114 .

12. Schwartz AL, Landon BE, Elshaug AG, Chernew ME, McWilliams JM. Measuring low-value care in Medicare. JAMA Intern Med 2014;174:10671076.

13. Organisation for Economic Co-operation and Development. Geographic Variations in Health Care: What Do We Know and What Can Be Done to Improve Health System Performance? Paris: OECD Publishing; 2014.

14. Coronini-Cronberg S, Bixby H, Laverty AA, Wachter RM, Millett C. English National Health Service's savings plan may have helped reduce the use of three 'low-value' procedures. Health Aff (Millwood). 2015;34:381-389.

15. McAlister FA, Lin M, Bakal J, Dean S. Frequency of low-value care in Alberta, Canada: a retrospective cohort study. BMJ Qual Saf 2018;27:340-346

16. Shi L. Health services research methods. Clifton Park: Thomson/Delmar Learning; 2008.

17. Kemper CJ. External Validity. In: Zeigler-Hill V, Shackelford TK, eds. Encyclopedia of Personality and Individual Differences. Cham: Springer International Publishing; 2017:1-4.

18. Colla CH, Morden NE, Sequist TD, Schpero WL, Rosenthal MB. Choosing wisely: prevalence and correlates of low-value health care services in the United States. J Gen Intern Med 2015;30:221-228.

19. Colla CH, Morden NE, Sequist TD, Mainor AJ, Li Z, Rosenthal MB. Payer type and low-value care: comparing Choosing Wisely services across commercial and Medicare populations. Health Serv Res 2018;53:730-746.

20. Zhou M, Oakes AH, Bridges JFP, Padula WV, Segal JB. Regional supply of medical resources and systemic overuse of health care among medicare beneficiaries. J Gen Intern Med 2018;33:2127-2131.

21. Oakes AH, Sen AP, Segal JB. Understanding geographic variation in systemic overuse among the privately insured. Med Care 2020;58:257264.

22. Health and Welfare Data Science Center. Database User Manual. Available at: https://dep.mohw.gov.tw/DOS/lp-3147-113.html. Accessed 29 March 2020.

23. Deyo RA, Cherkin DC, Ciol MA. Adapting a clinical comorbidity index for use with ICD-9-CM administrative databases. J Clin Epidemiol 1992;45:613-619.

24. Organisation for Economic Co-operation and Development. Health at a Glance 2017. Available at: https://www.oecd-ilibrary.org/content/publication/health_glance-2017-en. Accessed 31 November 2017.

25. Kravet SJ, Shore AD, Miller R, Green GB, Kolodner K, Wright SM. Health care utilization and the proportion of primary care physicians. Am J Med 2008;121:142-148.

26. Mossialos E, Djordjevic A, Osborn R, Sarnak D. International Profiles of Health Care Systems. Available at: http://www.commonwealthfund.org/ publications/fund-reports/2017/may/international-profiles. Accessed 31 May 2017.

27. Dailey AB, Kasl Sv, Holford TR, Calvocoressi L, Jones BA. Neighborhood-level socioeconomic predictors of nonadherence to mammography screening guidelines. Cancer Epidemiol Biomark Prev 2007; 16:2293-2303.

28. Prasad SM, Gu X, Lipsitz SR, Nguyen PL, Hu JC. Inappropriate utilization of radiographic imaging in men with newly diagnosed prostate cancer in the United States. Cancer. 2012;118:1260-1267.

29. Falchook AD, Salloum RG, Hendrix LH, Chen RC. Use of bone scan during initial prostate cancer workup, downstream procedures, and associated Medicare costs. Int J Radiat Oncol Biol Phys 2014;89:243248.

30. Falchook AD, Hendrix LH, Chen RC. Guideline-discordant use of imaging during work-up of newly diagnosed prostate cancer. J Oncol Pract 2015;11:e239-e246.

31. Ministry of Health and Welfare. Hospital establishment or expansion act. Available at: https://law.moj.gov.tw/LawClass/LawHistory.aspx?pcode = L0020163. Accessed 1 Nov 2018.

32. Chang HY, Bodycombe DP, Huang WF, Weiner JP. Risk-adjusted resource allocation: using Taiwan's National Health Insurance as an example. Asia Pac J Public Health. 2015;27:Np958-971.

33. Tung YC, Chang GM, Chang HY, Yu TH. Relationship between early physician follow-up and 30-day readmission after acute myocardial infarction and heart failure. PLoS One 2017;12:e0170061.

34. Chou YY, Yu TH, Tung YC. Do hospital and physician volume thresholds for the volume-outcome relationship in heart failure exist? Med Care 2019;57:54-62.

35. Segal JB, Bridges JF, Chang HY, et al. Identifying possible indicators of systematic overuse of health care procedures with claims data. Med Care 2014;52:157-163.

36. ABIM Foundation. Choosing Wisely. Available at: http://www choosingwisely.org/clinician-lists/american-academy-allergy-asthmaimmunology-uncomplicated-acute-rhinosinusitis/. Accessed 10 March 2019.

37. Cui J, Qian G. Selection of working correlation structure and best mode in GEE analyses of longitudinal data. Commun Stat Simul Comput 2007;36:987-996. 
38. Forrest CB, Starfield B. The effect of first-contact care with primary care clinicians on ambulatory health care expenditures. J Fam Pract 1996;43:40-48.

39. Xu WY, Jung JK. Socioeconomic differences in use of low-value cancer screenings and distributional effects in Medicare. Health Serv Res 2017;52:1772-1793

40. Choi Ww, Williams SB, Gu X, Lipsitz SR, Nguyen PL, Hu JC. Overuse of imaging for staging low risk prostate cancer. J Urol 2011;185:16451649 .

41. Dunnick NR, Applegate KE, Arenson RL. The inappropriate use of imaging studies: a report of the 2004 Intersociety Conference. J Am Coll Radiol 2005;2:401-406
42. O'Malley AS, Forrest CB, Feng S, Mandelblatt J. Disparities despite coverage: gaps in colorectal cancer screening among Medicare beneficiaries. Arch Intern Med 2005; 165:2129-2135.

43. Agency for Healthcare Research and Quality (2010) National Healthcare Quality and Disparities Reports. Available at: http://archive.ahrq.gov/ research/findings/nhqrdr/nhqrdr10/qrdr10.html. Accessed 7 Sept 2019

Publisher's Note: Springer Nature remains neutral with regard to jurisdictional claims in published maps and institutional affiliations. 